\title{
The Role of Sharing Economy in the Correction of Labor Alienation Based on the Analysis of Cooperative Game Theory
}

\author{
Wei Liping \\ Weifang University \\ Weifang, Shandong Province, China
}

\author{
Xie Miao \\ Liaoning University \\ Shenyang, Liaoning Province, China
}

\begin{abstract}
The labor alienation will inevitably make the differentiation between the rich and the poor, which will make the contradiction deepen between the trend of unlimited expansion of production and the demand of laborers with purchasing power, that is why the economic crisis will eventually outbreak again and again. It was no accident that the contemporary sharing economy just rose in the wake of the global financial crisis of 2008, the reason was that there contained the correction force for labor alienation in the business model of the contemporary sharing economy which can better meet the individual and customized needs of both supply and demand through everyone's participation and the use of internet sharing platforms. This paper analyzes the basic conditions for the change of labor share and the improvement of relations between labor and capital through the game model of labor cooperation. It reveals the deep causes of the sharing economy, and explains the corrective effect of the sharing economy on the alienation between the laborers and their labor products, the laborers and their labor behaviors and the relationship between people. This study can provide theoretical support and policy suggestions for the government's working direction and supporting levels on the sharing economic development.
\end{abstract}

Keywords-Sharing economy, Labor alienation, Correction, Cooperative game theory

\section{INTRODUCTION}

The idea of labor alienation was first proposed by Marx in the Manuscript of Economics Philosophy of 1844. Its main meaning has three levels: First, the labor behavior of laborers and their products have been alienated. Second, the laborer and his labor behavior itself have been alienated. Third, the relationship between people has been alienated. Under capitalism, capitalists increase the labor intensity and labor time of workers in order to pursue unlimited profits, the labor of laborers is alienated. On the cost of alienation, capitalists obtain a large number of products and huge profits, so the gap between the rich and the poor will increase. "The socialization of production and the capitalist private ownership of the means of production will inevitably lead to the contradiction between the trend of unlimited expansion of production and the need for laborers to have purchasing power." Therefore, the economic crisis and the social crisis will erupt again and again. The last crisis in 2008 once again sparked the

This paper is the phase research result of 2017 Shandong Social Science Planning and Financial Project, named "The sustainable mechanism for poverty alleviation of Shandong province from financial perspective", and the project number is $17 \mathrm{CJRJ} 09$ discussion of this problem. As the Economist Stiglitz says in his book The Price of Inequility, after the crisis, people from Egypt, Spain, Greece, Great Britian, and the United States went onto the street, protesting against the unfairness with their political and economic system. For example, young protestors from Spain put out a slogan of "generation of anger". Their anger came from over $40 \%$ unemployment rate. The protestors on the Wall Street shouted: "we are $99 \%$ of the population", indicating the situation that $99 \%$ of the population was experiencing the sharp decrease in income.

We note, however, that it was also after the economic crisis of 2008 that a new form of economic business quickly emerged: the sharing economy. The sharing economy is a business model that better meets the personalized and customized needs of both supply and demand through the participation of everyone and the use of the Internet sharing platform. However, it is in this new economic form that we find the correction power of labor alienation.

In the middle of 20th century, especially after the Second World War, the labor and capital gradually realized that cooperating closely, reducing conflict, and the profit sharing moderately are win-win paths. At the same time, the realization form of the private ownership system has undergone significant change, workers began to share the profit and the emphasis of theoretical research also changed from the conflict coordination to incentive mechanism. After 2008, the sharing economy has risen rapidly in the global wide, it becomes not only the urgent task for the theoretical producers to work out a way to solve the problem of the serious imbalance of income distribution, but also the purpose of this text to seeking ways to improve the labor share through the cooperation game theory model.

\section{THEORETICAL BASIS OF THE MODEL}

\section{A. The description of the model}

The basis of labor-capital game is that there is a common but not completely consistent interest among the players. This common interest is the creation of the surplus value which is the "efficiency" goal of the human value goals; the conflict of interest is the distribution of surplus value which is the "fairness" goal of the human value goals. Pursuit of "efficiency" regardless of "fairness" or "fairness" regardless of" efficiency" will result in non-cooperative game, that is, 
one game party will choose only the advantageous strategy which is ignoring or even dangerous to the other party. The cooperative game emphasizes the indecisiveness of personal strategy, that is, individual decision will not have direct consequences on the individual income, but will affect the behavior of the other party, and produce a "non-linear" result through the changes of the behavior of the two parties. In this case, the parties' actions are allowed to be coordinated through the agreement, which is binding on both parties, includes the common interests of both parties, and can achieve greater self and common interests. The following game model is to analyze the key factors affecting the "bargaining" and the ways to increase the bargaining power of the vulnerable workers.

\section{B. The basic elements of the model}

1) The content chosen by the game party

Labor-capital bargaining game has two game parties, they are capital owner game party and the worker party, we referred to as game partyl and game party2. The content chosen by the game parties in the non-cooperative game is different from the strategy of their own. The content chosen by both parties in the cooperative game is the distribution plan containing the interests of both parties, which is denoted as $\mathrm{s}=$ $\left(\mathrm{s}_{1}, \mathrm{~s}_{2}\right)$, where $\mathrm{s}_{1}$ and $\mathrm{s}_{2}$ represent the interests of two game parties. Distribution subject to the conditions and basic requirements of the constraints, for example, the distribution must meet the interests of both sides and not more than the profits created, such as $\mathrm{R}$, then the interests of both parties must be between $0-R$, otherwise it will be unfavorable to both parties or at least one party will not accept it. Such allocation is called feasibility distribution and expressed as a set $\mathrm{S}=$

$\left\{\left(\mathrm{s}_{1}, \mathrm{~s}_{2}\right) \mid 0 \leq \mathrm{s}_{1} \leq \mathrm{R}, \mathrm{s}_{1}+\mathrm{s}_{2} \leq \mathrm{R}\right\}$, where $\mathrm{i}=1,2$ and $\mathrm{R}$ is the maximum distributable profit.

\section{2) Risk attitude of the game party}

We use $\mathrm{u}=\left(\mathrm{u}_{1}, \mathrm{u}_{2}\right)$ to express, where $\mathrm{u}_{1}$ and $\mathrm{u}_{2}$ represent the expected utilities of the two game parties, respectively. The real function $u_{\mathrm{i}}: \mathrm{S} \rightarrow \mathrm{R}$ that allocates the set $\mathrm{S}$ to the real number set, it is generally a function of the interests of the players themselves $\mathrm{u}_{\mathrm{i}}=\mathrm{u}_{\mathrm{i}}(\mathrm{s})=\mathrm{u}_{\mathrm{i}}\left(\mathrm{s}_{\mathrm{i}}\right)$. All possible utility configurations form a "utility configuration set," which is an image of a viable allocation function that is convex.

\section{3) Disagreement point}

Any negotiation has the possibility of rupture. When the negotiation is broken, the interest of both parties is called "Disagreement point of negotiation", or "Disagreement point" for short, with $\mathrm{d}=\left(\mathrm{d}_{1}, \mathrm{~d}_{2}\right)$, where $\mathrm{d}_{1}$ and $\mathrm{d}_{2}$ represent the interests of the two game parties as they break the negotiations. The break point is $(0,0)$ when both parties have no interest and the agreement fails to reach an agreement as negotiations broke down, The rupture of the negotiation point may also have an impact on the attitude and results of both parties. The game parties will not accept the profit distribution $\mathrm{s}_{\mathrm{i}}<\mathrm{d}_{\mathrm{i}}$ below the break point, and utility is generally an increasing function of interest, si $<$ di is consistent with $\mathrm{u}_{\mathrm{i}}\left(\mathrm{s}_{\mathrm{i}}\right)<\mathrm{u}_{\mathrm{i}}\left(\mathrm{d}_{\mathrm{i}}\right)$. That is to say, "bargaining" cooperation game is meaningful, at least one distribution $s \in S$ is required, and $u_{i}(s)>u_{i}(d)$ is satisfied for $\mathrm{i}=1,2$.

\section{4) Symmetry problem}

The question of "bargaining" can be perfectly symmetrical or asymmetrical. The so-called symmetry means that the bargaining sides have no difference in position, utility function, rupture, etc. They can be expressed by the symmetry of the utility configuration set, that is, $\left(\mathrm{u}_{1}, \mathrm{u}_{2}\right) \in \mathrm{U}$, then $\left(\mathrm{u}_{2}, \mathrm{u}_{1}\right) \in \mathrm{U}$; The so-called asymmetry means that both parties differ in at least one of the above aspects. Therefore, whether the relationship and status of "bargaining" parties are symmetrical also has a great impact to the attitude and outcome of both parties.

So far, the basic elements of the "bargaining" problem are already available. We can use $B\left(S, d ; u_{1}, u_{2}\right)$, where $S$ is the feasible distribution set, $\mathrm{d}$ is the breaking point, $\mathrm{u}_{1}$ and $\mathrm{u}_{2}$ are the two utility function.

\section{The basic axioms applicable to the model}

Cooperative games can make use of binding agreements, so the outcome of the game is determined by the joint rational actions of the game parties. What kind of allocation and utility allocation must be considered when analyzing a "bargaining" game is most likely to be accepted by both parties, this is the basic axiom that the model must apply.

\section{1) Pareto efficiency axioms}

According to realistic experience, the distribution accepted by both bargaining parties generally meets the basic requirements of both efficiency and fairness. In terms of efficiency requirements, there are two levels, maximizing overall profit and Pareto efficiency, as the former may contradict individual rationality and not necessarily be accepted by the bargaining parties, so it is excluded from this model, while Pareto efficiency is the basic requirement the model must meet. Pareto efficiency axiom is expressed as: If both $\left(\mathrm{s}_{1}, \mathrm{~s}_{2}\right)$ are the points in the set of feasible assignments for the "bargaining" problem and $\mathrm{u}_{1}\left(\mathrm{~s}_{1}\right)>\mathrm{u}_{1}\left(\mathrm{~s}_{1}{ }^{\prime}\right), \mathrm{u}_{2}\left(\mathrm{~s}_{2}\right)>$ $\mathrm{u}_{2}\left(\mathrm{~s}_{2}{ }^{\prime}\right)$, then $\left(\mathrm{s}_{1}{ }^{\prime}, \mathrm{s}_{2}{ }^{\prime}\right)$ will certainly not be the solution to the bargaining cooperative game. [1]

\section{2) Symmetry axioms}

The distribution accepted by both bargaining parties also needs to meet the need of fairness, that is, people demand fair treatment, and people often refuse to accept it if they consider it unfair to bring about greater benefits. If both parties are symmetrical, it is generally accepted that both parties receive the same treatment. Symmetry axioms can be expressed as follows: If $\mathrm{B}\left(\mathrm{S}, \mathrm{d}, \mathrm{u}_{1}, \mathrm{u}_{2}\right)$ is a symmetric bargaining problem, the condition that satisfies $\left(\mathrm{u}_{1}, \mathrm{u}_{2}\right) \in \mathrm{U}$ is $\left(\mathrm{u}_{2}, \mathrm{u}_{1}\right) \in \mathrm{U}$ and $\mathrm{d}_{1}=\mathrm{d}_{2}$, then the solution $\left(\mathrm{u}_{1} *, \mathrm{u}_{2} *\right)$ as the game must satisfy $\mathrm{u}_{1} *=\mathrm{u}_{2}$ * . In reality, not all the problems of "bargaining" are symmetrical, and the reason that causes the asymmetry of the game between the two sides is often the difference between the broken points of negotiation. In this case, we can transform the symmetric "bargaining" problem by considering the increase $u_{i}(s)-u_{i}(d)$ of net utility relative to the point of rupture.

\section{3) Linear transformation invariance axiom}

Factors that affect the symmetry of the "bargaining" issue include not only the point of rupture but also the players 
themselves, such as the game parties may have different enjoyment ratios for the same income gains, etc., These changes do not actually affect the preference structure, so the effects of these factors can generally be represented by the affine variation of the utility function, $u 1^{\prime}=a_{1}+b_{1} u_{1}, u_{2}{ }^{\prime}$ $=a_{2}+b_{2} u_{1}$. The invariance theorem of linear transformation can be expressed as: If $\left(\mathrm{s}_{1} *, \mathrm{~s}_{2} *\right)$ is the solution to a "bargaining" problem, then $\left(\mathrm{s}_{1} *, \mathrm{~s}_{2} *\right.$ )remains the "bargaining" solution as the utility in the "bargaining" problem is transformed to ui' $=\mathrm{a}_{\mathrm{i}}+\mathrm{b}_{\mathrm{i}} \mathrm{u}_{\mathrm{i}}$.

\section{4) Independent of the choice of axioms}

When the game player has different preference structure caused by risk attitude and utility preference, the theoretical "bargaining" utility configuration set can be very irregular and can not be transformed into a symmetric set by linear transformation. In this case, the asymmetric utility configuration set can be extended to a symmetric utility configuration set by adding an "unrelated" allocation scheme that will not actually be selected, using "If an optimal solution with a larger choice of range problem is within a smaller range of one, then the optimal solution in this small range is the conclusion of the optimal solution to the large-scale problem", which leads to the solution of "bargaining". Independent Choice axioms can be expressed as: If $\mathrm{B}\left(\mathrm{S}, \mathrm{d} ; \mathrm{u}_{1}, \mathrm{u}_{2}\right)$ and $\mathrm{B}\left(\mathrm{S}^{\prime}, \mathrm{d}^{\prime} ; \mathrm{u}_{1}, \mathrm{u}_{2}\right)$ are two "bargaining" questions and satisfy $\mathrm{S}$ contains $\mathrm{S}$ 'and $\mathrm{d}=\mathrm{d}$ ', then $\left(\mathrm{s}_{1} *, \mathrm{~s}_{2} *\right)$ must also be the solution of $\mathrm{B}\left(\mathrm{S}^{\prime}, \mathrm{d}^{\prime} ; \mathrm{u}_{1}, \mathrm{u}_{2}\right)$ if the cooperative game solutions $\left(\mathrm{s}_{1} *, \mathrm{~s}_{2}\right.$ * ) of $\mathrm{B}\left(\mathrm{S}, \mathrm{d} ; \mathrm{u}_{1}, \mathrm{u}_{2}\right)$ corresponding to $\left(\mathrm{u}_{1} *, \mathrm{u}_{2} *\right)$ fall in $\mathrm{S}^{\prime}$.

\section{Nash solution of the model}

The only solution to the "bargaining" problem of labor and capital that satisfies the above four axioms at the same time are the solution of the following constraint optimization problem:

$$
\begin{aligned}
& \operatorname{Max}\left[\left(\mathrm{u}_{1}(\mathrm{~s})-\mathrm{u}_{1}(\mathrm{~d})\right)\left(\mathrm{u}_{2}(\mathrm{~s})-\mathrm{u}_{2}(\mathrm{~d})\right)\right] \\
& \mathrm{s}_{1}, \mathrm{~s}_{2} \\
& \text { S.T. }\left(\mathrm{s}_{1}, \mathrm{~s}_{2}\right) \in \mathrm{S},\left(\mathrm{s}_{1}, \mathrm{~s}_{2}\right) \geqslant\left(\mathrm{d}_{1}, \mathrm{~d}_{2}\right)
\end{aligned}
$$

Nash solution is the optimal point of the nonlinear optimization problem, and the objective function of the optimization problem is also called Nash product. Because Nash products are generally concave functions, utility configuration sets are generally convex sets, so the optimization problem usually has the only solution. Taking the profit $\mathrm{R}=100$ created by the distribution of labor and capital as an example, according to the actual situation, the capital owner gains profits for capital appreciation, while the worker earns income first to survive. We assume that the capital owner's game 1 is risk-neutral, while the worker side game 2 is risk aversion, the utility functions of the two parties are as follows:

$$
\mathrm{u}_{1}=\mathrm{u}_{1}\left(\mathrm{~s}_{1}\right)=\mathrm{s}_{1}, \mathrm{u}_{2}=\mathrm{u}_{2}\left(\mathrm{~s}_{2}\right)=\mathrm{sb}_{2}, \mathrm{~b}<1
$$

Suppose the breaking point of labor-capital game negotiation is $(0,0)$, then the distribution condition must satisfy $\mathrm{s}_{1}+\mathrm{s}_{2} \leq 100$; the utility configuration must satisfy $\mathrm{u}_{1}+\mathrm{u}_{1} / \mathrm{b}_{2} \leq 100$. To analyze the bargaining problem of labor and capital by Nash solution is to solve the following constrained optimization problem of Nash product:

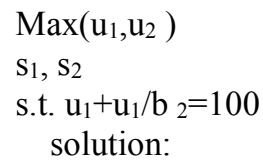

$$
\begin{gathered}
\mathrm{u}_{1} *=\mathrm{s}_{1} *=\frac{100}{1+\mathrm{b}} \\
\mathrm{s}_{2} *=100-\mathrm{s}_{1} *=\frac{100 b}{1+\mathrm{b}}
\end{gathered}
$$

Pictured as:

$\mathrm{u}_{2}$

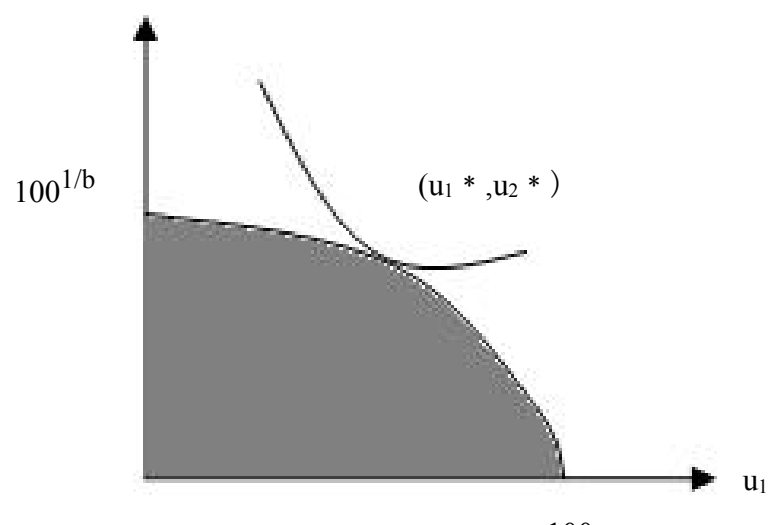

100

$\left(\mathrm{u}_{1} *, \mathrm{u}_{2} *\right)$ is the tangent point in the graph, that is, Nash solution.

\section{INSPIRATIONS OF THE MODEL}

1. The above model tells us that the differences in risk appetite between the "bargaining" parties have a clear effect on the outcome. The differences in the distribution of the two parties' incomes first depend on the setting of risk appetite. The assumption of risk neutrality in party1 is derived from the inherently strong position of the Chinese employers in the labor-capital game: The employer of capital is the owner of the means of production, and the mode of production of the capital employed labor makes the employers have natural advantages; Employers know that the workforce is always oversupplied, so the distribution plan is usually put forward by him. The smaller $b$ is, the more serious the risk aversion is for the labor, the smaller the distribution and the less utility. The above means that the laborer has the natural weak characteristic in the game between the two sides. The power of market cannot achieve both efficiency and fairness, it is necessary to carry out systematic outside intervention. [2]

2 . When $b=0$, that is, the game party 2 completely applies the attitude of risk aversion, it will gain nothing in the profit distribution. This is very much in line with the actual situation of the early days of capitalism: In the early days of capitalist development, labor was manifested as wage labor because the means of production belonged to the capitalists. Under the "wage-labor" system, the labor force of workers is incorporated into capital as an essential element of capital, so that the labor of the workers belongs to the capitalist. In order to maintain the reproduction of the labor force of the hired worker, the capitalist pays the worker part of the value of the labor equivalent to v. And the capitalist regards the surplus- 
value $\mathrm{M}$ as their own which relies on the ownership of the factor of production, including the hired worker's labor force. This determines that wage-earners and capitalists have very unequal status and power within the enterprise. They can only get the value of the labor force that barely survives, and sometimes the income is still below the value of the labor force. It can be seen that in the early stages of capitalist development, the laborers completely lost the ability to bear risks, which is the root cause of labor alienation and deepening. [3]

3. When $b>0$, I, e. Game party 2 is less dependent on risk aversion; the worker begins to participate in the distribution of profits, that is the era of sharing is coming. Historically, this was caused by a change in terms of employment. At the beginning of the 20th century, with the development of science and technology, the socialization of production continued to increase, and the scale of enterprises was constantly expanding The level of operation in the competition played an increasingly important role. The original capital owners, due to the increasingly difficult business operations, began to delegate part or all of their business decision-making power to managerial staff without capital through the principal-agent relationship, so the quest for maximizing capital gains has finally led to the separation of capital from ownership. However, the principal-agent relationship arising from the separation of the two rights in capital poses a challenge to the traditional wage-labor system, in which the owner of the capital possesses the full residual value. Because of differences in motivation, symmetry of information and degree of reciprocity of responsibilities between capital owners and managers, labor starts not completely subordinate to capital, such as: From the point of view of the driving force, the owners of capital are for the sake of proliferation and the capital managers are for higher income. Therefore, the managers will ignore the long-term interests for short-term interests. In order to reduce the cost of supervision and mobilize the enthusiasm of the operators, the capital owner has to give up some of the residual claims, enabling the operator to obtain a residual income that is directly related to the operation and management in addition to the fixed income. This is the residual sharing system in the modern enterprise. It is also the manager's participation as the earliest batch of laborers in the distribution of surplus value. [4]

4. The advantage of "bargaining" Nash solution lies in the fact that it embodies the requirements of fairness and efficiency on the one hand, and on the other hand, it shows the welfare of both sides at the same time. This is the development path of modern sharing economy and it is also a fundamental revision of the phenomenon of labor alienation. First, the participation of everyone in the shared economy reflects the revision of the labor of workers and the alienation of their labor products. The power of platform owners in the shared economy generally depends on the degree of user participation. Therefore, the management is no longer the main owner and controller of the product, and the laborers have played a decisive role in it; Second, the sharing platform in the shared economy reflects the correction of the alienation of workers and their labor behavior itself. The biggest feature of the shared economy is the flexible and diverse employment methods. [5] According to the 2015 Internet Trends Report, the number of freelancers in the United States has reached 53 million. And this is possible because shared economic platforms provide opportunities for this group to increase their income, from Crowdsourcing platforms such as the Pig Eight Ring Network, Mission China, and Renren Express. The O2O home service to the living area has cultivated large-scale free employment opportunities and part-time employment groups, allowing participants to enter or leave the social production process more freely, fully respecting the labor will of workers; Finally, the matching of supply and demand in the shared economy forms a correction to the alienation of interpersonal relations, and the traditional labor model in the shared economy is replaced by the production model of "laborershared platform-consumer", which is inspired by the goal of maximizing income. Workers, entrepreneurs, consumers and other micro-entities spontaneously play interactions, break the original organizational model, reconstruct labor relations, and eventually form new organizational forms. Objectively, it is not necessary to rely on the existence of corporate organizations, which greatly relieves the labor relationship and other related relations.

\section{CONCLUSION}

In summary, with the widespread use of Internet and mobile Internet technologies and big data, the sharing economy has gradually shifted and expanded from the distribution area to the production, exchange, and consumption areas. The contemporary shared economy emphasizes the separation of the right to use and ownership emphasizes the use of idle resources and the matching of immediate supply and demand. It has a significant effect on alleviating resource constraints and alleviating the burden of living costs brought about by workers due to declining income, and has become a new idea to solve the phenomenon of human labor alienation. For that reason, the State and the Government should not stand idly by, but should shoulder the responsibility of creating the conditions for the flourishing development of a shared economy and guiding its sound development.

\section{REFERENCE}

[1] Xie Shiyu. Economic Game Theory [M]. Shanghai: Fudan University Press. 2007, 329.

[2] Xie Pan, Li Wenbo, Liu Yu. Negotiation Status, Price Make-up and Labor-Capitalist Game[J]. China Higher Social Science, 2014.04

[3] Sun Huiwen. Negotiation Space, Negotiation Ability and Labor's Salary [J]. Economic System Reform, 2012.06.

[4] Wei Liping, "Development Trend of Sharing Economy in big data era based on Duplication Dynamic evolution game theory", Cluster Computing, February 2018.

[5] Xie Fusheng, Li An, Zhu Andong. Marxist Crisis Theory and Profit rate of American Economy in 1975-2008 [J]. Chinese Academy of Social Sciences, 2010.05 . 